\title{
Economic Impact on Postnatal Ossification
}

STANLEY M. GARN, SAM T. SANDUSKY, NANCY N. ROSEN AND FREDERICK TROWBRIDGE

Center for Human Growth and Development, The University of Michigan, Ann Arbor, Michigan 48104, and Center for Disease Control,

Atlanta, Georgia

KEY WORDS Ossification · Poverty · Income · Skeletal development.

\begin{abstract}
The magnitude of economic impact on postnatal ossification timing in generally lower-income boys and girls of European ancestry was found to be 0.21 standard deviation units or Z-scores for a difference of approximately $\$ 2200.00$ in per-capita income. Both boys and girls were equally affected.
\end{abstract}

While it is axiomatic that the children of the poor are developmentally delayed in comparison with boys and girls of greater affluence, the magnitude of the relationship between economic status and postnatal ossification timing has not been subject to direct quantification. Indeed, most published data on the age at appearance of the 28 postnatal ossification centers of the hand are given without reference either to family income or to indices of parental education and occupation that relate to economic status.

In the present study, therefore, we have made use of postero-anterior hand radiographs of 1790 boys and girls generally from lower-income families, collected from eight states during the 1968-1970 Nutrition Survey. Two of the states were from the Northeast (Massachusetts and New York), two represented Appalachia (West Virginia and Kentucky), two of the states were from the Pacific Coast (California and Washington), and the remaining two represented the old South and the upper Midwest, i.e., South Carolina and Michigan, respectively.

For each individual, economic status was calculated as the income-needs ratio, a widely-used measure that incorporates (a) total household income, (b) the number and the age of members of the household and (c) the baseline or "poverty level" income (Orshansky, '65). Two contrasting groups were then selected for comparison. The first, comprising all of the boys and girls with an income-needs ratio of 1.50 and less, had a mean income-needs ratio falling slightly below the accepted poverty level of 1.0. The second group, with in come-needs ratios of 2.25 and above, was a higher income group, averaging approximately three times the poverty-income level. On a per-capita basis, the mean in come for the first group was $\$ 724.00$, and that for the second group was $\$ 2920.00$ per capita. The per-capita income range was therefore $\$ 2200.00$, on a group basis.

For all of the children in the study, the age at appearance of postnatal ossification centers was computer-derived from (a) birth date, (b) examination date and (c) presence-absence information as initially recorded on optical scanning cards. The mean value (M) was calculated as the midpoint of a Gaussian distribution, and the standard deviation $(\sigma)$ was generated from the cumulative frequency curves (cf. Garn et al., '72). In all, six wrist area centers were selected for comparison, covering the range from the first through the seventh year, since the sample did not allow calculation of age at appearance of early postnatal centers.

As shown in table 1 , the more affluent boys and girls (income-needs ratios above 2.25) were systematically earlier in age at appearance of wrist area centers than children of poorer families (income-needs ratios up to 1.50), and without exception. This trend was statistically significant by sign test at any reasonable level of confidence, since for 12 pairs of comparisons, the more affluent were advanced in all 12 pairs as against the $6: 6$ or chance hypothesis $\left(\chi^{2}>8.0\right)$. Most individual ossification centers were also significantly advanced at the $5 \%$ level of confidence, 
TABLE 1

Income and ossification timing of wrist area centers

\begin{tabular}{|c|c|c|c|c|c|c|c|c|c|c|c|c|}
\hline \multirow{4}{*}{ Center } & \multicolumn{6}{|c|}{ Boys } & \multicolumn{6}{|c|}{ Girls } \\
\hline & \multicolumn{4}{|c|}{ Income-needs group } & & & \multicolumn{4}{|c|}{ Income-needs group } & & \\
\hline & \multicolumn{2}{|c|}{ Lower 1} & \multicolumn{2}{|c|}{ Higher ${ }^{2}$} & \multicolumn{2}{|c|}{ Difference } & \multicolumn{2}{|c|}{ Lower 1} & \multicolumn{2}{|c|}{ Higher ${ }^{2}$} & \multicolumn{2}{|c|}{ Difference } \\
\hline & $\mathbf{N}$ & M & $\mathbf{N}$ & M & Years & $\mathrm{Z}$ & $\mathbf{N}$ & M & $\mathbf{N}$ & M & Years & $\mathbf{z}$ \\
\hline Triquetral & 467 & 2.81 & 159 & 2.24 & 0.57 & 0.34 & 270 & 1.71 & 83 & 1.33 & 0.38 & 0.33 \\
\hline Lunate & 458 & 4.16 & 248 & 3.78 & 0.38 & 0.23 & 352 & 3.20 & 80 & 2.85 & 0.35 & 0.28 \\
\hline Scaphoid & 448 & 6.12 & 242 & 5.98 & 0.14 & 0.10 & 337 & 4.46 & 163 & 4.30 & 0.16 & 0.14 \\
\hline Trapezium & 573 & 6.36 & 242 & 6.14 & 0.22 & 0.14 & 411 & 4.39 & 135 & 4.20 & 0.19 & 0.13 \\
\hline Trapezoid & 403 & 6.19 & 242 & 6.09 & 0.10 & 0.08 & 399 & 4.55 & 127 & 4.40 & 0.15 & 0.13 \\
\hline Distal ulna & 500 & 7.33 & 231 & 7.07 & 0.26 & 0.21 & 371 & 6.02 & 143 & 5.61 & 0.41 & 0.34 \\
\hline \multirow{2}{*}{\multicolumn{5}{|c|}{$\begin{array}{l}\text { Mean difference }(Z) \\
\text { Mean per cent difference } 3\end{array}$}} & & 0.18 & & & & & & 0.23 \\
\hline & & & & & & 6.00 & & & & & & 7.67 \\
\hline
\end{tabular}

1 Income-needs group through 1.49, mean per-capita $\$ 724.00$.

2 Income-needs group 2.25 and above, mean per-capita income $\$ 2920.00$.

3 Conception corrected, $M+0.75$.

or better, since individual standard errors (s.e.) were between 0.05 and 0.11 standard deviation (S.D.) units.

Expressed in Z-scores or standard deviation units, relative to the total group, mean differences in postnatal ossification timing were 0.18 S.D. (for boys) and 0.23 S.D., for girls. As percents of age at appearance, corrected to conception ages, the differences were of the order of $6-7 \%$, overall. Within the limits of the generally lower-income sample, and without consideration of a probably non-linear relationship at the higher levels of affluence, it may be calculated that there is an ossification timing advance of 0.1 standard deviation units for each $\$ 1000.00$ of percapita income.

To be sure, family income and the composition of the household are by no means the only determinants of postnatal ossification. Our previous twin, sibling and parent-child comparisons have detailed the extent to which genetic factors affect timing and sequence (Hertzog, Falkner and Garn, '69; Garn, Rohmann and Davis, '63; Garn, Rohmann and Silverman, '67). Geographical origins also affect postnatal ossification timing, for boys and girls of largely-African ancestry are skeletally advanced over their peers of European derivation by nearly 0.5 standard deviations, and slightly more when matched for the income-needs ratio (Garn et al., '72). Furthermore, the criterion of income or income relative to needs does not fully express such contributory variables as parental care, maternal education, nutritional knowledge, use of the food dollar and access to medical care. Still, the relationship between the income-needs ratio and/or per-capita income and postnatal ossification timing is clearly delineated.

With these precautionary statements to warn against over-interpretation, there is also a very real need to caution against under-interpretation in the present findings. It is reasonable to suggest that money does buy things that improve growth and speed development - food, clothing, shelter and medical care. The two economic levels contrasted -1.50 and 2.25 - in the income-needs ratio, are not rags to riches, but more nearly poverty to some degree of comfort, the latter not quite equal to $\$ 9000.00$ for a family of four.

Considering the fact that the limited economic range here considered is associated with a 6-7\% mean difference in ossification timing, approximating 0.2 standard deviation units or Z-scores, it is also reasonable to suggest that absolute differences in ossification timing between Boston and Cleveland samples (cf. Pyle, Waterhouse and Greulich, '71, p. 36) may reflect economic differences in the subject samples. This is also likely for our Southwestern Ohio data of far later date of collection (cf. Garn, Rohmann and Silverman, '67). Delayed ages at ossification in the earlier European literature, and in more 
recent studies from South Africa, New Guinea and Central America, clearly reflect problems of data interpretation.

Future studies of postnatal ossification timing may need to be far more specific on both economics and ancestry, since both of these variables relate to timing, as we show here and in our comparative study (Garn et al., '72). For archaeological populations, of course, even ossification data on the least affluent American children may be inappropriate, and for this purpose ossification estimates may be based upon highly-delayed village populations in the Middle East (cf. Forbes et al., '71).

\section{ACKNOWLEDGMENTS}

The work described in this paper was carried out under Contract HSM 21-72522 (P), many of the calculations were completed by Jerrold $M$. Nagy and the manuscript was completed by Shirley $M$. Garrett.

\section{LITERATURE CITED}

Forbes, A. P., H. A. Ronaghy and M. Majd 1971 Skeletal maturation of children in Shiraz, Iran. Am. J. Phys. Anthrop., 35: 449-454.

Garn, S. M., C. G. Rohmann and A. A. Davis 1963 Genetics of hand-wrist ossification. Am J. Phys. Anthrop., $21: 33-40$.

Garn, S. M., C. G. Rohmann and F. N. Silverman 1967 Radiographic standards for postnatal ossification and tooth calcification. Med. Radiog. Photog., 43: 45-66.

Garn, S. M., S. T. Sandusky, J. M. Nagy and M. B. McCann 1972 Advanced skeletal de velopment in low-income Negro children. J. Pediat., 80: 965-969.

Hertzog, K. P., F. Falkner and S. M. Garn 1969 The genetic-determination of ossification sequence polymorphism. Am. J. Phys. Anthrop., 30: 141-143.

Orshansky, M. 1965 Counting the poor: Another look at the poverty profile. Soc. Sec. Bull., 28: 3-29.

Pyle, S. I., A. M. Waterhouse and W. W. Greulich 1971 A Radiographic Standard of Reference for the Growing Hand and Wrist. The Press of Case Western Reserve University, Chicago. 